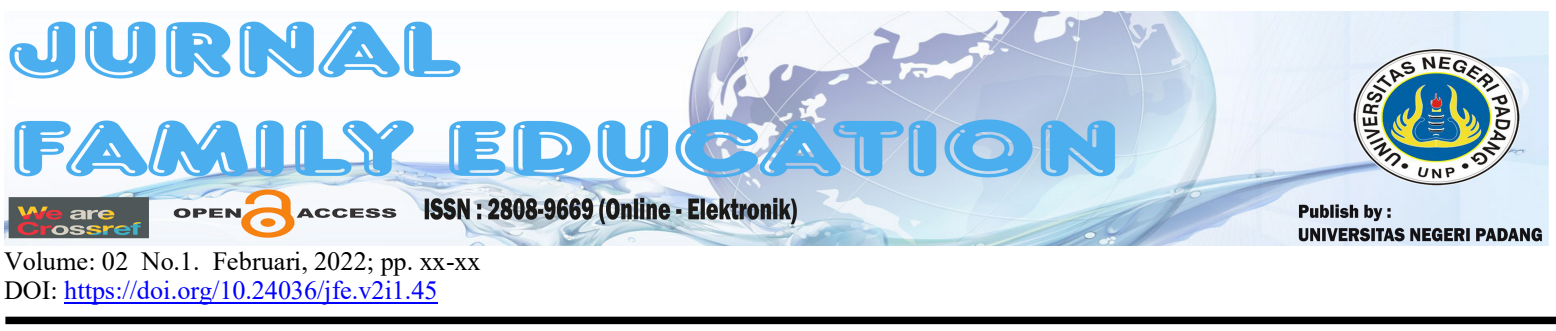

\title{
Pengaruh Penggunaan Media Video Terhadap Hasil Belajar Mata Pelajaran Ipa Pada Program Kesetaraan Paket B
}

\author{
Silfia Pratiwi, Syur'aini \\ Universitas Negeri Padang \\ * e-mail: Silfiapratiwi42@gmail.com
}

\begin{abstract}
The background of this research is the lack of activeness of students in learning science subjects in the Package B Equivalence Program because the media used by tutors does not vary. This results in low student learning outcomes. This study aims to describe student learning outcomes by applying video media to science subjects and to see the effect of applying video media to learning outcomes in the Package B Equivalence Program. The approach used in this research is a quantitative experimental type with a posttest-only control group model. . All students of the Package B Equivalence Program at PKBM Sentosa Hati class IX became the population in this study. The samples were taken using simple random sampling technique from class IXA and IXB. Researchers collect data using tests. Data analysis using t-test technique. The results of this study are: 1) the learning outcomes of students who do not use video media have a low average; 2) the learning outcomes of students who were given video media treatment had a high average; and 3) there is a significant effect between the use of video media on the learning outcomes of students' science subjects in the Package B Equivalence Program.
\end{abstract}

Keywords: Media Video, Hasil Belajar, IPA

\section{PENDAHULUAN}

Pada era globalisasi ini sangat banyak masyarakat yang mengalami putus sekolah yang diakibatkan dari segala aspek, salah satunya ialah faktor ekonomi yang kurang, serta kurangnya pemahaman terhadap pentingnya pendidikan dan sebagainya. Dengan banyaknya masalahmasalah yang ditemukan dalam pendidikan formal, untuk itu Pendidikan Luar Sekolah mengambil peran sebagai pelengkap, penambah serta pengganti dari pendidikan formal.

Untuk mengatasi hal itu Pendidikan Luar Sekolah memiliki wadah untuk menyelesaikan masalah-masalah tersebut. Beberapa bentuk dari Pendidikan Luar Sekolah yaitu PKBM. PKBM merupakan sebuah tempat yang berisikan pengetahuan tentang kegiatan belajar tanpa batas usia yang dilaksanakan untuk masyarakat agar dapat digunakan dari, oleh dan untuk masyarakat. PKBM memiliki salah satu program yang bisa membantu masyarakat yang kurang beruntung dalam hal pendidikannya, salah satunya yaitu program pendidikan kesetaraan. Pendidikan kesetaraan ialah suatu wujud pendidikan nonformal, yaitu Pendidikan paket A sepadan SD/MI, paket B sepadan SMP, dan Paket C yang sepadan dengan SMA. (Ramadani \& Syuraini, 2018). 
Pelaksanaan sekolah kesetaraan tidak luput dari berbagai permasalahan -permasalahan. Dimana karakteristik warga belajar di kejar paket cukup heterogen baik dari segi usia, pengelaman, latar belakang, sikap bahkan minat belajar dan lain sebagainya. Untuk itu menuntut tutor untuk merancang sebuah perencanaan pembelajaran yang sesuai dengan karakteristik warga belajarnya.

Pemakaian media yang pas dan memadai bisa dapat memberikan rangsangan untuk dapat berfikir krtitis dan menambah pengetahuannya serta menambahkan keinginan untuk belajar agar pelaksanaan pembelajaran bisa dikatakan baik. Pemanfaatan media yang mencukupi diharapkan bisa memicu partisipan peserta didik agar bisa atensi belajar sehingga proses pendidikan bisa berjalan dengan baik Dadang and Mamad (2012). Media pembelajaran bermanfaat sebagai memperlancar hubungan antara pemberi materi kepada penerima materi dan menjadikan kegiatan belajar semakin bermakna (Sari, Solfema, \& Syuraini, 2019). Sedangkan pemanfaatan media video sangat jarang atau bisa dikatakan belum pernah menggunakan media pembelajaran video.

Dari pengamatan ditemukan banyaknya permasalahan-permasalahan dalam proses pembelajaran. Pada pelaksanaan pembelajaran terdapat peserta didik yang tidak berkonsentrasi dalam mengikuti pembelajaran, berbicara bersama teman, melamun bahkan ada yang bermain hp disaat tutor menyampaikan materi. Dengan proses pembelajaran yang berpusat dengan tutor, peserta didik bersikap pasif yang terbiasa menerima sesuatu yang disampaikan tutor sehingga pembelajaran di kelas hanya berjalan secara satu arah. Ini mengakibatkan peserta didik tidah paham dengan materi dan menjadikan hasil belajarnya rendah.

Menurut Daryanto (2010) bahwa dengan menerapkan media video diharapkan peserta didik dapat menangkap serta mencerna dan mengenali pesan atau materi dengan baik, ini dikarenakan peningkatan tingkat daya ingat dan daya serap akan terjadi secara kuat jika proses diterimanya materi dan informasi awal lebih besara menggunakan dua panca indera yaitu indera penglihatan dan juga pendengaran. Serta pengaplikasian media dalam proses pembelajaran juga dapat mempengaruhi kemauan, motivasi, dan ketertarikan peserta didik dalam belajar (Mutmainnah \& Ismaniar, 2018). Dengan demikian media video juga dapat menarik minat dan juga mampu memberikan peningkatan terhadap hasil yang diperoleh peserta didik kegiatan belajar.

Dalam proses pembelajara IPA yang materi pembelajarannya sangat banyak menjelaskan tentang struktur organ manusia, hewan bahkan tumbuhan menjadikan media video menjadi media pembelajaran yang efektif dan efisien. Menurut Lusidawaty 2020 dikutip dari (Sunami, 2021) mengatakan bahwa pembelajaran IPA adalah mata pelajaran wajib yang diajarkan sebab banyak belajar tentang alam dan aktivitas sehari-hari, serta mata pelajaran ini mempelajari dan menjelaskan mengenai penemuan, melaksanakan praktek dan dihubungkan dengan teori dalam proses belajar.

Dari berbagai rasional serta berbagai masalah yang dikemukakan tadi, peneliti memiliki ketertarikan untuk melakukan penelitian mengenai "Pengaruh Penggunaan Media Video terhadap Hasil Belajar Mata Pelajaran IPA pada Program Kesetaraan Paket B”.

\section{METODOLOGI PENELITIAN}

Penelitian ini dilakukan dengan menggunakan pendekatan kuantitatif berjenis eksperimen dengan model Posttest-only control group design, dengan populasi ialah seluruh warga belajar paket B di PKBM Sentosa Hati kelas IX berjumlah 50 orang. Menurut Yusuf (2007), Sampel adalah sesuatu yang tertentu dari unsur yang terpilih dari suatu populasi. Pengambilan sampel dilakukan dengan menggunakan teknik random sampling, yang dilakukan secara acak tanpa membandingkan strata (Sugiyono, 2016). Berikut tabel sampel dan populasi: 
Tabel 2. Sampel dan Populasi

\begin{tabular}{|c|c|c|}
\hline Kelas & Populasi & Sampel \\
\hline IX. A & 25orang & 15 orang \\
\hline IX. B & 25 orang & 15 orang \\
\hline Jumlah & 50 orang & 30 orang \\
\hline
\end{tabular}

Penelitian ini menggunakan teknis tes pilihan ganda yang berisikan tentang pemberitahuan atau keterangan akan belum lengkapnya suatu pengertian. Dalam peneltian ini peneliti menggunakan test obyektif yang dikenal dengan istilah test jawaban pendek. Test ini berisi beberapa soal yang harus dijawab oleh testee dengan memberikan jawaban yang dianggap benar. Setiap butir soal apabila dijawab dengan betul maka akan memperoleh skor 1 (satu), tetapi apabila jawabannya salah, akan memperoleh skor 0 (nol). Uji statistik yang penelitia gunakan dalam penelitian ini, yakni uji-t. Sebelum menjalankan uji-t, diuji normalitas dan keseragaman untuk mengetahui distribusi normal dan varians seragam pada pertanyaan. Maka didapat dari uji normalitas dengan rumus Kolmogorov Smirnov, bisa dilihat pada table bahwa besaran nilai signifikansi kelas kontrol ialah $0.91>0.05$, maka nilai residual kelas kontrol termasuk normal. Hal tersebut sejalan dengan besaran nilai signifikansi kelas eksperimen ialah $0.2>0.05$ yang membuktikan bahwa nilai residual kelas eksperimen termasuk normal juga. Hasil uji homogenitas dapat disimpulkan diperoleh lebih besar nilai signifikansi dari kedua kelas dibandingkan nilai standar signifikan 0.05, yaitu untuk hasil Kelas Kontrol $0.142>0.05$, sedangkan untuk Kelas Eksperimen ialah $0.101>0.05$. Untuk itu dapat dinyatakan bahwa varian data hasil belajar pada keals control dan eksperimen sebagai varians normal dan seragam.

\section{HASIL PENELITIAN Deskripsi Hasil Belajar}

Post test hasil belajar IPA pada kelas control dan eksperimen didapat setelah melaksanakan proses pembelajaran dengan melalukan perlakuan (Treatment). Perlakuan disini berupa pemberian media pembelajaran video dengan materi "sistem reproduksi tumbuhan dan hewan". Setelah diberikan perlakuan peserta didik diminta untuk mengisi soal post-test. Post-test ini berisikan soal objektif sejumlah 20 soal dan peserta didik diinstruksikan untuk menjawab pertanyaan yang dianggap paling benar.

Hal ini terlihat pada histogram hasil belajar pada kelas eksperimen dengan rata-rata skor ialah 89 dengan nilai minimum yaitu 80 sebanyak 4 orang dan nilai maksimum yaitu 100 sebanyak 3 orang.

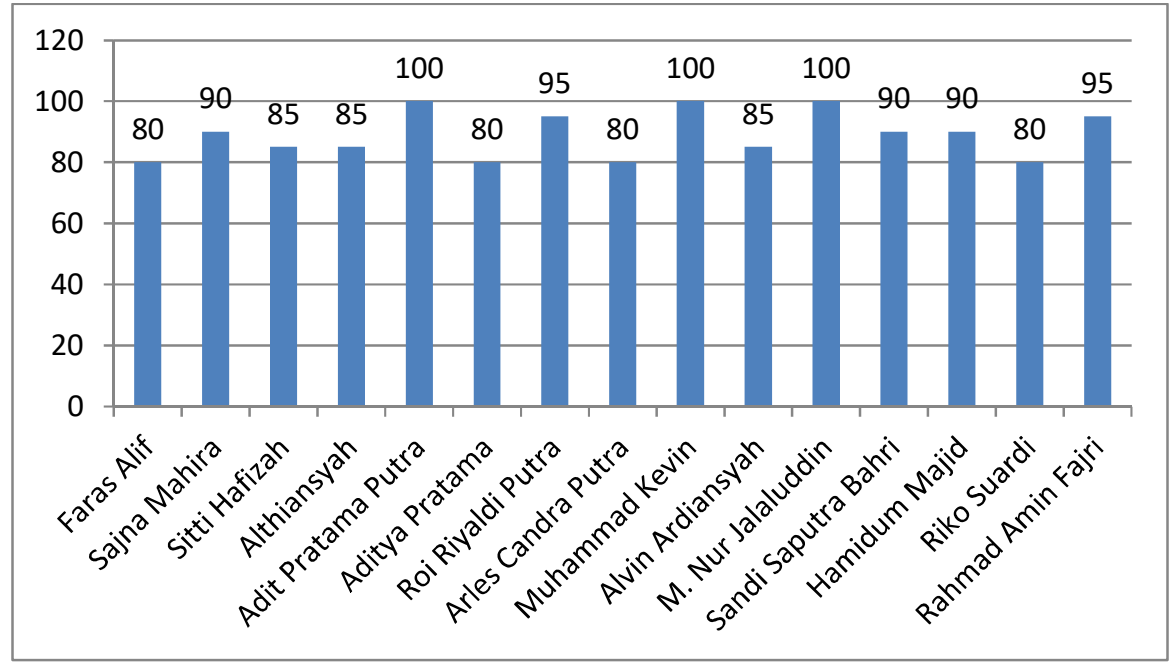

Gambar 1. Gambar Histogram Hasil Belajar Posttest Kelas Eksperimen Jurnal Family Education

Open Access Journal 


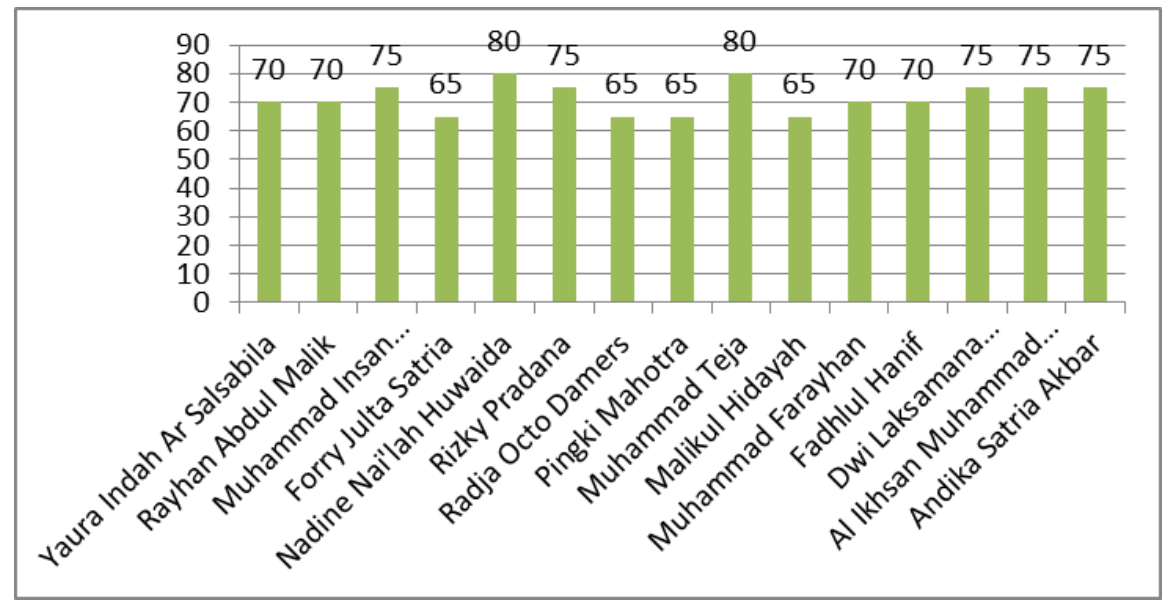

Gambar 2. Histogram Hasil Belajar Posttest Kelas Kontrol

Sedangkan hasil belajar kelas kontrol dapat diketahui dari histogram hasil belajar kelas kontrol dengan rata-rata 71,66 dengan nilai minimum yaitu 65 sebanyak 4 orang dan nilai maksimum yaitu 80 sebanyak 2 orang.

Berdasarkan histogram diatas, dapat dilihat terdapat signifikansi perbedaan hasil belajar antara kelas yang memanfaatkan media video untuk pembelajaran (eksperimen) dan kelas yang memanfaatkan media buku dan juga papan tulis (kontrol).

\section{Pengaruh Penggunaan Media Video terhadap Hasil Belajar Mata Pelajaran IPA di PKBM Sentosa Hati}

Pengujian uji $\mathrm{t}$ dengan menggunakan rumus $\mathrm{t}$ test untuk melihat pengaruh pemanfaatan media video terhadap hasil belajar mapel IPA. Adapun penghitungan hasil uji t data disajikan pada table di bawah ini:

Tabel 2. Hasil Uji t

\begin{tabular}{|c|c|l|}
\hline Jenis uji & Statistik & \multicolumn{1}{c|}{ Kesimpulan } \\
\hline Uji t & $\begin{array}{c}\text { thitung }=7,191 \\
\mathrm{t} \text { tabel }=2,048\end{array}$ & $\begin{array}{l}\mathrm{H}_{\mathrm{a}} \text { diterima dan } \mathrm{H}_{0} \text { ditolak, maka terdapat } \\
\text { pengaruh penggunaan media video terhadap hasil } \\
\text { belajar. }\end{array}$ \\
\hline
\end{tabular}

Setelah melakukan uji t, dapat diketahui adanya perbedaan yang signifikan pada hasil belajar dengan menghasilkan nilai $\mathrm{t}_{\text {hitung }}$ yaitu 7,191 dengan $(\mathrm{dk})=\mathrm{n} 1+\mathrm{n} 2-2=28$ dengan $\alpha=0,05$ maka diperoleh nilai $t_{\text {tabel }}$ yaitu 2,048. Dengan perolehan $t_{\text {htung }}>t_{\text {tabel }}$ maka dapat disimpulakn bahwa $\mathrm{H}_{\mathrm{a}}$ diterima dan $\mathrm{H}_{0}$ ditolak. Dengan demikian, peneliti menyimpulkan bahwasanya terdapat pengaruh penggunaan media video terhadap hasil belajar mata pelajaran IPA.

\section{PEMBAHASAN}

Sebuah proses pembelajaran akan dikatakan berhasil jika sudah memenuhi komponenkomponennya seperti tujuan, materi, metode, guru, sarana prasarana materi, tujuan, metode, sarpras, guru, dan lainnya. Pendidikan dan media pebelajaran dapat dikatakan sebagai unsur yang saling berkesinambungan dalam dunia pendidikan. Pemakaian media yang pas dan memadai bisa menstimulasi peserta didik untuk dapat berpikir krtitis dan menambah pengetahuannya serta menambahkan keinginan untuk belajar agar pelaksanaan pembelajaran bisa dikatakan baik. Penggunaan media pembelajaran membuat semangat yang dimiliki oleh warga belajar lebih tinggi lagi, maka dari itu tutor harus menggunakan media dalam setiap pembelajaran sehingga motivasi 
dan minat warga belajar tetap bagus untuk mengikuti setiap kali pertemuan dalam pembelajaran (Syuraini \& Yolanda, 2019).

Keberhasilan dalam proses pembelajaran juga bisa dihitung dengan kesanggupan peserta didik dalam mendalami sebuah materi pelajaran. Tolak ukur dari berhasilnya proses pembelajaran ini dapat ditentukan dengan sampai mana pemahaman peserta didik akan materi yang diberikan pendidik. Apabilasebagian besar peserta didik dapat memahami materi guru, pembelajaran dapat dikatakan berhasil.

Media video menjadi variabel yang akan dilihat pengaruhnya dengan hasil belajar peserta Program Kesetaraan Paket B dikarena media video inilah yang dijadikan media belajar di sana. Karena itu perlu dilihat apakah penggunaan media belajar menggunakan video memberikan pengaruh kuat pada hasil belajar peserta didik dengan cara memberikan perlakukan yang berbeda dengan dua kelas yaitu ada satu kelas yang tidak memanfaatkan media video sebagai media belajarnya dan kelas satu lagi yang memanfaatkan media video sebagai media belajarnya. Pada kelas eskperimen, dilakukan penelitian dengan menggunakan media video youtube dengan materi tentang sistem reproduksi hewan dan tumbuhan. Media pembelajaran video diputar menggunakan LCD proyektor. Cecep Kustandi dan Bambang Sutjipto dalam Nugroho (2015) mengatakan bahwa media video dapat digunakan untuk media pembelajaran, sebab video meneskripsikan suatu obyek yang bergerak sejalan dengan kesesuaian suranya. Pada saat pembelajaran dengan media video, tutor menayangkan media video dan meminta peserta didik untuk menyimak serta memperhatikan video hingga selesai. Peserta didik terlihat tertarik dalam proses pembelajaran menggunakan media video ini. Setelah menyimak video yang ditampilakn, peserta didik bersama tutor berdiskusi mengenai materi yang dibahas dalam media video tersebut. Dapat dilihat antusias dan semangat peserta didik dalam belajar menggunakan media terkhususnya media video.

Penelitian pada kelas kontrol dilakukan dengan menggunakan materi yang sama, yakni "Sistem Reproduksi Tumbuhan dan Hewan" tetapi menggunakan media buku, spidol dan juga papan tulis. Disini tutor menjelaskan materi dengan metode ceramah dan sesekali melakukan diskusi bersama peserta didik. Namun terlihat peserta didik banyak tidak fokus dalam pembelajaran, berbeda dengan kegiatan belajar dengan memanfaatkan media video.

Kriteria dalam mengambil kesimpulan hipotets dalam penelitian ini, yaitu apabila $t_{\text {hitung }}>t_{\text {tabel }}$ maka dapat dikatakan $\mathrm{H}_{\mathrm{a}}$ diterima dan $\mathrm{H}_{0}$ ditolak. Hal tersebut menunjukkan adanya perbedaan kuat antara kelas eksperimen dan kontrol. Setelah melakukan uji t (t-tets), diketahui hasil penelitian ialah adanya perbedaan yang signifikan dengan menghasilkan nilai thitung yaitu 7,191 dengan $(\mathrm{dk})=\mathrm{n} 1+\mathrm{n} 2-2=28$ dan $\alpha=0,05$ dan didapatkan nilai $t_{\text {tabel }}$ yaitu 2,048. Dengan perolehan $t_{\text {htung }}>t_{\text {tabel }}$ maka dapat disimpulakn bahwa $\mathrm{H}_{\mathrm{a}}$ diterima dan $\mathrm{H}_{0}$ ditolak. Jadi, ditarik kesimpulan bahwasanya ada perbedaan secara signifikan antara penggunaan media video terhadap hasil belajar mata pelajaran IPA.

Hal tersebut sejalan dengan pendapat Daryanto dalam Al Fasyi (2015) mengatakan bahwa lebih mudahnya peserta didik dalam menyerap dan mengingat materi dengan optimum jika belajar menggunakan media video, hal ini dikarenakan ketika proses memperoleh informasi pertama kali dilakukan melalui visual dan suara, dalam hal ini menggunakan media video sebagai media pembelajaran, daya ingat dan daya serap peserta didik sangat meningkat. Ketika terjadi peningkatan daya ingat dan daya serap, akan berpengaruh terhadap hasil belajar peserta didik. Ini dapat dibuktikan pada kelas eksperimen bahwasanya pemanfaatan media video dapat mempercepat peserta didik untuk menyerap serta menangkap materi belajar dengan menggunakan kedua inderanya.

Dikarena penelitian ini melakukan eksperimen terhadap kelas yang memamnfaatkan video sebagai media belajar dan ada kelas yang tidak memanfaatkan media video untuk belajar, dan hasilnya menunjukkan bahwa kelas yang memanfaatkan media video yang memperoleh hasil belajar lebih tinggi bisa dijadikan rujukan dalam pembelajaran selanjutnya, yaitu memberikan pembelajaran setiap kelas menggunakan media video. Hal itu akan membantu meningkatkan hasil belajar peserta didik sebab adanya bantuan dari media video. Simpulan yang dapat diperoleh 
adalah bahwa media pembelajaran berupa video berpengaruh terhadap hasil belajar peserta didik pada Program Kesetaraan Paket B. Kelas yang menggunakan video sebagai media belajarnya ratarata memperoleh hasil belajar lebih tinggi daripada kelas yang tidak memanfaatkan media video pada saat pembelajarannya. Selain melihat dari hasil belajar yang didapat pada kelas yang memanfaatkan media video ketertarikan serta antusias peserta didik pada saat menggunakan media video juga terlihat meningkat. Terlihat dari pemberian pembelajaran dengan menggunkan media video peserta didik terlihat antusias serta menimbulkan respon yang baik selama proses pembelajara. Jadi, dapat disimpulkan bahwasanya media video memiliki pengaruh signifikan terhadap hasil belajar mata pelajaran IPA pada Program Kesetaraan Paket B.

\section{KESIMPULAN}

Sesuai dengan hasil penelitian dan pembahasan tentang penelitian yang berjudul Pengaruh Penggunaan Media Video terhadap Hasil Belajar Mata Pelajaran IPA Program Kesetaraan Paket B, dapat disimpulkan: 1). Hasil belajar peserta didik Program Kesetaraan Paket B yang tidak menggunakan media video sebagai media belajar pada saat belajar IPA mempunyai rata-rata yang rendah. 2). Hasil belajar peserta didik Program Kesetaraan Paket B yang diberikan perlakuan menggunakan media video pada saat belajar mata pelajaran IPA mempunyai rata-rata yang tinggi. 3). Adanya pengaruh signifikan antara penggunaan media video terhadap hasil belajar mata pelajaran IPA peserta didik pada Program Kesetaraan Paket B yang ditandai oleh nilai $t$ tabel $>t$ hitung. Artinya dengan adanya penerapan media video dalam pembelajaran akan berpengaruh yang kuat terhadap keberhasilan belajar peserta didik.

\section{SARAN}

Pada penellitian ini, dapat dikemukakan saran, antara lain:

1. Berdasar pada dari hasil penelitian ini, adanya perbedaan yang signifikan antara pembelajaran menggunkan media video dengan tanpa menggunakan media video. Untuk itu diharapkan kedepannya pembelajaran pada Program Kesetaraan Paket B menggunakan media belajar, salah satunya media video.

2. Penggunaan media video hendaknya diberikan pada setiap kelas sehingga bisa memperoleh hasil yang sama terhadap semua kelas. Dengan menyelenggarakan pembelajaran sesuai kebutuhan dengan cara yang tepat, diharapkan akan berdampak besar bagi keberhasilan belajar peserta didik.

3. Pihak lembaga lebih meningkatkan lagi sarana dan prasarana dalam menunjang proses pembelajaran, khususnya fasilitas dalam penggunaan media video.

4. Diharapkan untuk peneliti selanjutnya mencari variabel lain yang memberikan pengaruh terhadap hasil belajar pada Program Kesetaraan Paket B dan mencari kajian secara mendalam mengenai teori-teori yang menyangkut dalam media pembelajaran.

\section{Daftar Rujukan}

Afriana, R., Wisroni, W., \& Setiawati, S. (2018). Hubungan antara Komunikasi Interpersonal Tutor dengan hasil Belajar Bahasa Inggris Warga Belajar Bahasa Inggris Warga Belajar Kelas VIII Paket B di PKBM Sakindo, (2010). https://doi.org/10.24036/spektrumpls.v1i1.9010

Al Fasyi, M. C. (2015). Pengaruh Penggunaan Media Video Terhadap Hasil Belajar IPA Siswa Kelas IV SD Negeri Ngoto Bantul Yogyakarta Tahun Ajaran 2014/2015. Universitas Negeri Yogyakarta. Retrieved from https://eprints.uny.ac.id/

Dadang, S., \& Mamad, K. (2012). Pembelajaran Mikro. Bandung: UPI Press.

Darmawati, D., \& Dalle, A. (2019). Hypermedia: Aplikasi Pembelajaran Bahasa Arab di Era 
Digital. Parepare: CV. Kaaffah Learning Center. Retrieved from http://repository.iainpare.ac.id/836/1/Hypermedia.pdf

Elfa, E., \& Irmawita, I. (2020). The Relationship Between Instructors' Teaching Skills and The Learning Outcomes of The Learning Community at PKBM Surya Padang. SPEKTRUM: Jurnal Pendidikan Luar Sekolah, 8(4). https://doi.org/10.24036/spektrumpls.v8i4.110102

Etana, N., \& Sunarti, V. (2021). Relationship Between Learning Strategies and Students' Learning Outcomes at Taqwa Pandam TPA. SPEKTRUM: Jurnal Pendidikan Luar Sekolah, 9(4). Retrieved from http://103.216.87.80/index.php/pnfi/article/view/114015/105769

Fahyuni, E. F. (2017). Teknologi, Informasi, dan Komunikasi (Prinsip dan Aplikasi dalam Studi Pemikiran Islam). Sidoarjo: Umsida Press.

Irmawita, I. (2018). Pengelolaan Program Pendidikan Nonformal untuk Kelompok Masyarakat Lanjut Usia. KOLOKIUM: Jurnal Pendidikan Luar Sekolah, 6(1). https://doi.org/10.24036/kolokium-pls.v6i1.2

Mukhlis, S. K., \& Irmawita, I. (2021). The Relations of Tutor Teaching Performance and Science Learning Outcome of Learners at Paket B Equivalency Program. SPEKTRUM: Jurnal Pendidikan Luar Sekolah, 9(3). Retrieved from http://103.216.87.80/index.php/pnfi/article/view/113400/105492

Mutmainnah, F., \& Ismaniar, I. (2018). Hubungan antara Media Pembelajaran Fiqih Menurut Peserta Didik dengan Motivasi Belajarnya di MDA. Spektrum: Jurnal Pendidikan Luar Sekolah (PLS), 1(4), 432. https://doi.org/10.24036/spektrumpls.v1i4.101746

Nilam, R., \& Setiawati, S. (2021). The Relationship Between Learning Motivation and Learning Outcomes of 3 in 1 Training Participants of Manual Embroidery Clothing. SPEKTRUM: Jurnal Pendidikan Luar Sekolah, 9(4). Retrieved from http://103.216.87.80/index.php/pnfi/article/view/113875/105766

Nugroho, T. A. T. (2015). Pengaruh Media Video Pembelajaran Terhadap Keterampilan Proses dan Hasil Belajar IPA di Kelas V SD Negeri Rejowinangun 1 Yogyakarta. Jurnal Pendidikan Guru Sekolah Dasar, IV(6). Retrieved from https://eprints.uny.ac.id/16596/1/Skripsi_Thomas Adi Tri Nugroho_11108244081.pdf

Oktavia, G., Wisroni, W., \& Syuraini, S. (2018). Hubungan antara Kepuasan Kerja dengan Kinerja Tutor Paket C di PKBM Karang Taruna Kembang Delima. KOLOKIUM: Jurnal Pendidikan Luar Sekolah, 6(1), 54-64. https://doi.org/10.24036/kolokium-pls.v6i1.6

Putri, R., \& Jamna, J. (2021). The Relationship Between Music Accompaniment Learning Media with the Learning Outcomes of the Skills of Minangkabau Traditional Dance Training Participants at The Baiturrahmah Studio Padang City. SPEKTRUM: Jurnal Pendidikan Luar Sekolah, 9(2). Retrieved from http://103.216.87.80/index.php/pnfi/article/view/112369/105384

Ramadani, F., \& Syuraini, S. (2018). Gambaran Kompetensi Profesional Tutor Menurut Warga Belajar pada Program Kesetaraan Paket B di PKBM Legusa Kabupaten Lima Puluh Kota. Spektrum: Jurnal Pendidikan Luar Sekolah (PLS), 1(4), 423. https://doi.org/10.24036/spektrumpls.v1i4.101721

Rita, Y., \& Handrianto, C. (2021). Innovation of Digital Learning in Package C Program in Facing the New Normal Education. KOLOKIUM Jurnal Pendidikan Luar Sekolah, 9(1), 20-29. https://doi.org/10.24036/kolokium-pls.v9i1.447

Sari, P. N., Solfema, S., \& Syuraini, S. (2019). The Difference Participant of Wirid Remaja in Wirid Remaja Activities Using and Not Using Powerpoint Media in Kelurahan Air Tawar Timur. Spektrum Jurnal Pendidikan Luar Sekolah, 7(2). https://doi.org/10.24036/spektrumpls.v2i2.9515

Sugiyono. (2016). Metode Penelitian Kuantitatif, Kualitatif, dan Kombinasi (Mixed Methods). Bandung: Alfabeta.

Sugiyono. (2017). Metode Penelitian Kuantitatif, Kulaitatif, dan R\&B. Bandung: Alfabeta.

Sunami, M. A., \& Aslam, A. (2021). Pengaruh Penggunaan Media Pembelajaran Video Animasi Berbasis Zoom Meeting terhadap Minat dan Hasil Belajar IPA Siswa Sekolah Dasar. Jurnal 
Basicedu, 5(4). Retrieved from https://jbasic.org/index.php/basicedu/article/view/1129

Sunarti, V. (2014). Peranan Pendidikan Luar Sekolah dalam Rangka Mitigasi Bencana. Spektrum: Jurnal Pendidikan Luar Sekolah (PLS), 2(2). https://doi.org/10.24036/spektrumpls.v2i2.5044

Syuraini, S., \& Yolanda, Y. (2019). Use of Learning Media in Entrepreneurship Subjects Equality Education Paket C. KOLOKIUM: Jurnal Pendidikan Luar Sekolah, 7(1), 48-52. https://doi.org/10.24036/kolokium-pls.v7i1.18

Yarissumi, Y. (2017). Hubungan antara Konsentrasi Belajar Peserta Didik Dengan Keaktifan Belajarnya pada Bimbingan Belajar Bahasa Inggris Happy Course. KOLOKIUM Jurnal Pendidikan Luar Sekolah, 5(2). Retrieved from http://kolokium.ppj.unp.ac.id/index.php/kolokium-pls/article/view/31/31 